\title{
Editorial: Internet addictions
}

\author{
Daniel King \\ School of Psychology, The University of Adelaide, Australia
}

Dear researchers, colleagues, and readers interested in research on the internet and technology,

it is a pleasure to introduce this special issue on "Internet addictions" for Cyberpsychology: Journal of Psychosocial Research on Cyberspace. In this issue, we feature several new articles on a diverse range of topics which we trust will be of interest to readers. As many working in this field can attest, there is often much debate on several conceptual issues around the topic of problems and disorders related to online platforms and activities. Is Internet addiction a valid disorder? Does the term offer clarity and practical utility, or does it confuse problems that can occur both online and offline? Does it misdirect attention from more clinically relevant explanations for excessive technology use? Does it open the door to a new wave of disorders - Facebook addiction, Twitter addiction, Snapchat addiction, Pokemon Go addiction, Virtual Reality addiction - of dubious validity and clinical utility?

We present this issue with full acknowledgement of these conceptual dilemmas. The term 'Internet' appears often to be employed not only to refer to a range of activities that occur online, but also to the medium in which activities can take place. This distinction is important but often overlooked. Having a label like Internet addiction with some perceived face validity for the scientific community to rally around and collect our empirical observations and generate critical discussion can nevertheless have practical utility. This is particularly evident in East Asian regions where there have been significant efforts and advances in policy, prevention, and treatment to address Internet overuse, largely as a result of public pressure and academic studies united by the umbrella term of Internet addiction. Many laudable international efforts, however, do not entirely assuage the confusion and ambiguity in terms of diagnostic considerations. A person with gambling disorder who gambles online is not really an Internet addict, but rather a type of problem gambler. A person who spends a lot of time online and avoids real life social situations may be socially anxious, not an Internet addict. A person may use the Internet intensely for a couple of months, resulting in some sleepless nights and a few arguments with a partner, and then spontaneously stop and reduce use to healthy levels. Again, this is not an Internet addict. This is new territory in which clinicians and other stakeholders should tread cautiously, and make responsible decisions based on the best available evidence.

The DSM-5 recognises Internet gaming disorder (including gaming that occurs offline) in Section III as a condition warranting further study, but it does not recognise 'Internet addiction' per se. Although there are some advantages to having a 'label', there are also potential pitfalls to accepting an Internet-related disorder in diagnostic systems. First, this might lead to an excited flurry among researchers to propose many other onlinerelated activities in clinical nomenclature as disorders, without a credible reason for doing so. The early definitional criteria of problematic gaming were largely informed by researchers in the problem gambling and substance addictions fields. The terms 'gambling' or 'alcohol' were simply removed and substituted with 'gaming' in screening survey and case report studies. Having an 'Internet gaming disorder' classification might encourage some opportunistic researchers to simply substitute the names of other online activities, in a bid to deliver the coveted 'first scale' (followed by the short, shortened and shortest versions). I believe that we are already seeing 
this troubling phenomenon with the frequent creation of new screening tools and measures, each one designed for a new activity or a new population irrespective of their similarity to existing scales. As one case in point, we now have a problematic Tinder use scale - so why not add a scale for problematic use of OKCupid, LoveFlutter, or Bumble (and for the record, I have never heard of any of them). Going back to 2012, I counted 18 measures for problematic gaming and that number has only increased dramatically with the DSM-5. It is a major problem for the field, as it works to establish its credibility, to have newcomers and experienced clinicians sift through its bank of inconsistent approaches to screening. The way forward is not in creating more new scales in rebadged, translated, expanded, or streamlined formats, but for more rigorous testing of the existing approaches as well as clinical studies that examine in qualitative depth the nature of the problem.

A final point I would like to make is a call for researchers and others with an interest in Internet addiction to think more broadly, beyond the scope of addiction theory, about the psychological function of the activities that would be labelled harmful. We should always remember that the Internet or a video game is not the same as packet of cigarettes. Research does not suggest that each and every hour or dose of game play has a measurable negative physical and/or psychological impact to the player. What attracts so many millions of people to online games and other activities, and how can we leverage this information for useful purposes? Can it help us to understand the differences between normal and pathological use? To inform therapy goals? It is important that we do not lose sight of the potential benefits that many new technologies grant to users, and consider this knowledge to inform useful definitions and guidelines of healthy use. The above mentioned issues and others prompted spirited debate among the editorial team in considering submissions for this special issue. We hope that readers of this issue are similarly stimulated by the four presented papers.

The first paper by Michelle Drouin and Daniel Miller examines the links between Internet addiction and engagement in online erotica among a large group of men in the United States. The study examines the extent to which use of pornography and sex websites may mediate the relationship between Internet addiction and risky sexual online behaviour. Their findings have several interesting treatment implications related to therapeutic targets for change among this group of Internet addicts.

The second paper by Van Zalk examines social anxiety as a moderator of excessive online chatting and compulsive Internet use among adolescents. The presented findings are provocative in suggesting that, although anxiety is a prevalent and serious psychological disorder, social anxiety may have some secondary effects such as limiting time spent online for some young people and thereby reduce their risk of developing compulsive online behaviours.

The third paper by Tracii Ryan and colleagues examines different types of problematic Facebook users. Using a cluster analysis, this study and its findings reflect on the extent to which different people may develop problems with Facebook use according to levels of socialising, gaming, and usage. Research of this nature is helpful because it can inform different perspectives on individuals and their psychological needs based on their usage and motivational profile.

The final paper by Lukas Blinka investigates dysfunctional impulsivity in relation to online gaming behaviours in a large Czech sample. This work offers new insights and reflection on the significance of impulsivity as a predictor of engaging in gaming at risky levels, which is of relevance to our understanding of the psychological profiles of problematic gamers as compared to gaming enthusiasts.

In preparation of this issue, I want to express my thanks to the Editor Prof. David Smahel for ongoing advice, collegial discussion, and support in reviewing papers. I am also grateful for the support of Lenka Dedkova for careful editing and management of the papers for this issue.

Dr Daniel King

School of Psychology

The University of Adelaide 


\section{Guest Editors of Special Issue "Internet Addictions"}

Daniel King, School of Psychology, The University of Adelaide, Australia

E-mail: daniel.king(at)adelaide.edu.au

David Smahel, Faculty of Social Studies, Masaryk University, Czech Republic

E-mail: smahel(at)fss.muni.cz

Lenka Dedkova, Faculty of Social Studies, Masaryk University, Czech Republic

E-mail: Idedkova(at)fss.muni.cz

\section{Issue Content}

Article 1:

Editorial: Internet addictions

Daniel King

doi: 10.5817/CP2016-3-1

Article 2:

Online erotica usage as a mediator between internet addiction and engagement in risky online sexual behaviors

Michelle Drouin and Daniel A. Miller

doi: 10.5817/CP2016-3-2

Article 3:

Social anxiety moderates the links between excessive chatting and compulsive Internet use Nejra Van Zalk

doi: 10.5817/CP2016-3-3

Article 4:

Who gets hooked on Facebook? An exploratory typology of problematic Facebook users

Tracii Ryan, John Reece, Andrea Chester and Sophia Xenos

doi: 10.5817/CP2016-3-4

Article 5:

Dysfunctional impulsivity in online gaming addiction and engagement

Lukas Blinka, Kateřina Škařupová and Kristina Mitterova

doi: 10.5817/CP2016-3-5

\section{About Journal}

The 'Cyberpsychology: Journal of Psychosocial Research on Cyberspace' is a web-based, peer-reviewed scholarly journal. The first peer-reviewed issue was published in September 2007. The journal is focused on social science research about cyberspace. It brings psychosocial reflections of the impact of the Internet on people and society. The journal is interdisciplinary, publishing works written by scholars of psychology, media studies, communication science, sociology, political science, nursing, ICT security, organizational psychology and also other disciplines with relevance to psychosocial aspects of cyberspace. The journal accepts original research articles, as well as theoretical studies and research meta-analyses. Proposals for special issues are also welcomed.

The journal is indexed with SCOPUS, ERIH PLUS, EBSCO Academic Search Complete, the Directory of Open Access Journals and the Czech Database of Scientific Journals. 
The articles in Cyberpsychology: Journal of Psychosocial Research on Cyberspace are open access articles licensed under the terms of the Creative Commons Attribution Non-Commercial License which permits unrestricted, noncommercial use, distribution and reproduction in any medium, provided the work is properly cited. The author of the work thus grants Cyberpsychology: Journal of Psychosocial Research on Cyberspace a non-exclusive license and all publishing rights are therefore left to the author without any further restrictions.

\section{Editor}

Prof. David Smahel, M.Sc. et Ph.D., Faculty of Social Studies, Masaryk University, Czech Republic

E-mail: smahel(at)fss.muni.cz

\section{Associate Editor}

Prof. Kristian Daneback, Ph.D., University of Gothenburg, Sweden

E-mail: kristian.daneback(at)socwork.gu.se

\section{Managing Editor}

Lenka Dedkova, Ph.D., Faculty of Social Studies, Masaryk University, Czech Republic

E-mail: Idedkova(at)fss.muni.cz

\section{Editorial Board}

Prof. Kaveri Subrahmanyam, Ph.D., California State University, Los Angeles, USA

Prof. Herbert Hrachovec, Ph.D., University of Vienna, Austria

Prof. Dr. Micheline Frenette, Universite de Montreal, Canada

Prof. Alexander E. Voiskounsky, Ph.D., Lomonosov Moscow State University, Russia

Prof. Michael W. Ross, Ph.D., DrMedSc, MPH, MPHEd, University of Texas, Houston, USA

Prof. Petr Macek, CSc., Masaryk University, Czech Republic

Prof. Olle Findahl, World Internet Institute, Sweden

Prof. Jochen Peter, Ph.D., University of Amsterdam, Netherlands

Prof. Veronika Kalmus, Ph.D., University of Tartu, Estonia

Prof. Joshua Fogel, Ph.D., Brooklyn College of the City University of New York, USA

Prof. Gustavo S. Mesch, Ph.D., University of Haifa, Israel

Prof. Lelia Green, Ph.D., Edith Cowan University, Australia

Prof. Michel Walrave, Ph.D., University of Antwerp, Belgium

Michelle Wright, Ph.D., Masaryk University, Czech Republic

Václav Štětka, Ph.D., Charles University, Czech Republic

Andra Siibak, Ph.D., University of Tartu, Estonia

Adjunct Prof. Birgit U. Stetina, Ph.D., University of Vienna, Austria

Lukas Blinka, Ph.D., Masaryk University, Czech Republic

\section{Advisory Board}

Prof. Bente Traen, Ph.D., University of Oslo, Norway

Prof. Charles Ess, Ph.D., University of Oslo, Norway

Prof. Dr. Ilse Kryspin-Exner, University of Vienna, Austria

Prof. PhDr. Jan Jirák, Ph.D., Charles University, Czech Republic

Prof. Vasja Vehovar, Ph.D., University of Ljubljana, Slovenia 
Prof. Larry D. Rosen, Ph.D., California State University, USA

Prof. Patricia M. Greenfield, Ph.D., University of California, USA

Prof. Peter K Smith, University of London, England

Prof. Nicola Döring, IImenau University of Technology, Germany

Prof. Kimberly Young, Ph.D., St. Bonaventure University, USA

Prof. Jos de Haan, Ph.D., Erasmus University, Netherlands

Prof. Zbyněk Vybíral, Ph.D, Masaryk University, Czech Republic

Prof. Monica Whitty, Ph.D., University of Leicester, UK

Prof. Alistair Duff, Ph.D., Edinburgh Napier University, Scotland

Assoc. Prof. Alfred Choi, Ph.D., Nanyang Technological University, Singapore

Prof. Thurasamy Ramayah, Universiti Sains Malaysia, Malaysia

Assoc. Prof. Neil Coulson, Ph.D., The University of Nottingham, UK

Assoc. Prof. Kenneth C. C. Yang, Ph.D., University of Texas at El Paso, USA

Assoc. Prof. Sun Sun Lim, Ph.D., National University of Singapore, Singapore

Prof. Sameer Hinduja, Ph.D., Florida Atlantic University, USA

Assoc. Prof. Jana Horáková, Ph.D., Masaryk University, Czech Republic

Assoc. Prof. Radim Polčák, Ph.D., Masaryk University, Czech Republic

Assoc. Prof. Pille Pruulmann-Vengerfeldt, Ph.D., University of Tartu, Estonia

Assist. Prof. Alexander Schouten, Ph.D., Tilburg University, Netherlands

Assist. Prof. Ewa S. Callahan, Ph.D., Quinnipiac University, USA

Assist. Prof. Regina van den Eijnden, Ph.D., Utrecht University, Netherlands

PhDr. Ing. Petr Soukup, Charles University, Czech Republic

Janis Wolak, Ph.D., University of New Hampshire, USA

Francesca Romana Seganti, Ph.D., Sapienza University of Rome, Italy

Jeff Gavin, Ph.D., University of Bath, UK

Hana Macháčková, Ph.D., Masaryk University, Czech Republic

Michael Fenichel, Ph.D., New York, USA

Leslie Haddon, Ph.D., London School of Economics, UK

\section{Publisher}

Masaryk University, Faculty of Social Studies

Jostova 10, 60200 Brno

Czech Republic

\section{Publication Schedule}

Four issues per year: two regular issues (in July and December) plus two special issues (between regular issues)

\section{About author}

Daniel King's research area is the study of digital technology-based addictions, with a specific interest in video games and online activities. He is also interested in the role of new digital technologies in gambling, including both monetary and non-monetary forms of gambling, and the potential risks posed to young people by these new avenues for gambling. He is the chief investigator on the South Australian Media Use Study (SAMUS), which is a large survey of SA-based adolescents' electronic media use and its impact on sleep, mental health, and social functioning. 